Journal of Engineering and Science Research 5 (3): 07-11, 2021

e-ISSN: 2289-7127

(C) RMP Publications, 2021

DOI: $10.26666 / \mathrm{rmp}$.jesr.2021.3.2

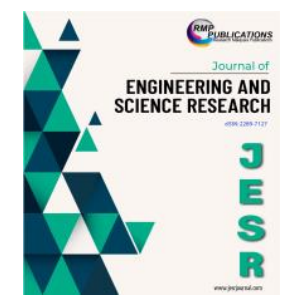

\title{
Safety Helmets for Motorcycle Rider with Hearing Impairment
}

\author{
Muhammad Hafiyuddin Bin Abdul Mutalib and Yew Been Seok \\ Faculty of Innovative Design and Technology, Universiti Sultan Zainal Abidin, Malaysia.
}

\begin{abstract}
Motorcycle fatal accidents on roads in Malaysia are one of the major causes of death and injuries. There is a need to increase and improvise road safety awareness. In Malaysia, riders with hearing impairment are allowed to ride a motorcycle on the road but restrictions such as responding to the surrounding sounds, especially the sounds produced by the horns and emergency siren from other vehicles warrant a high degree of concern. In this work, a safety helmet is designed to aid the rider with hearing impairment, in detecting the sounds produced by the horns and emergency siren of vehicles. A simple mechanism is developed by using sound sensors as the input, lightemitting diode (LEDs) as the output, and Arduino Uno Board as the controller. The threshold of the sound sensor is $96 \mathrm{~dB}$. When the sensor detected sound waves that exceed the threshold, the LEDs will turn on, which serves as the awareness indication for the rider with hearing impairment. The functionality of the sound detection mechanism in the designed safety helmet is tested based on its response to car and motorcycle horns. The sound intensity produced by car and motorcycle horns is in the range of $107-109 \mathrm{~dB}$ and $96-105 \mathrm{~dB}$. Respectively. The functionality test was conducted at three different distances starting from $4.7 \mathrm{~m}, 9.4 \mathrm{~m}$, and $14.10 \mathrm{~m}$ and the developed system operates to detect the sound of horns in the range of 120-90 dB. Finite element analysis was also performed in analyzing the carbon fiber material for the designed safety helmet, which shows the least deformation $(6.174 \mathrm{~mm})$ with the stress of $1014 \mathrm{MPa}$ resulting in the lowest strain of 0.01181 when the load of $3432 \mathrm{~N}$ was applied to it vertically. Safety helmets that impair hearing with hearing aids are crucial for riders with hearing impairment. However, this work implements an alternative method that focused on using visual warning signals instead of audible warning signals, in aiding the riders with hearing impairment, especially completely deaf riders to stay alert and safe on the road.
\end{abstract}

\section{Key words: Traffic fatality, Motorcycle, Hearing impairment, Emergency vehicle}

\section{INTRODUCTION}

The loss of hearing affects psychological, linguistic, and communication. Initially, the word "hearing impaired" was used to identify individuals with any degree of hearing loss, including those who are deaf and those who are hard of hearing, from moderate to profound [1].

Hearing impairments can exist either in both ears and just in the single ear [2]. Persons with hearing loss exceeding 90 decibels are termed deaf. In general, not every deaf communicator is considered "deaf." About 1 in 1,000 persons with hearing loss is critically deaf. They still can hear specific levels of listening; however, it is not sufficient to ensure reliability to acquire sign languages to communicate between them or with others. Sounds under the range of $20 \mathrm{~dB}$ can be heard by normal individuals. Below are the categories of hearing losses [3]:

- $\quad 15-30 \mathrm{~dB}$ hearing loss, slight hearing loss

- $\quad 31-60 \mathrm{~dB}$ hearing loss, medium hearing loss

- $\quad 61-90 \mathrm{~dB}$ hearing loss, critical hearing loss

- $\quad>90 \mathrm{~dB}$ hearing loss, extreme hearing loss

In Malaysia, riders with hearing impairment or deaf riders are allowed to drive a car or other vehicles. However, the influence of hearing loss to the traffic safety leads to high risk of road accidents compared to average road users $[4,5]$. There has been variety of warning signal approaches for the riders with hearing impairment or deaf riders. Flash a warning signal as a detection against sounds wave produced by

Corresponding Author: Yew Been Seok, Faculty of Innovative Design and Technology, Universiti Sultan Zainal Abidin, Malaysia, bseokyew@unisza.edu.my 
the siren has been proposed by Harvey and Thomas et.al $[6,7]$. However, the intensity of the flash signal is highly affected on broad daylight. Kuwahara et.al. proposed a mechanism which delivers vibration to the antebrachial area (forearm) of the driver and LED lights on the dashboard to indicate the type and location of the detected emergency vehicle [8]. However, the sensitivity of vibrations is highly affected by the road conditions, which may interrupt the effectiveness of the developed system.

In this work, a detection system using LED lights to notify deaf drivers of the approaching of an emergency vehicle has been proposed and developed. The developed system used sound sensor to detect the sound waves produced by vehicles depending on its frequency and sound waves. The visual output of the sound signals serves as an alternative to detect siren and recognizable output [8,9].

\section{Consequence of Deaf Drivers/Riders on Traffic Safety}

The effects of hearing impaired on road safety and mobility and the empirical results remain a global concern [10]. Hearing losses are one of the most common sensory defects in human beings, leading to the loss of auditory input, which can impact traffic actions and reduce traffic safety and mobility [11]. The incidence of acoustic hearing loss associated with age is growing, which would also increase the number of road users with hearing loss. Thus, there is a need to analyze the protection and mobility of traffic for people with hearing loss. The approach of tactile signal can improve driver assistance systems. This system is effective for all users as visual resources can be more focused on the road, which could increase both traffic safety.

As it applies to deafness and hearing impairment, there is no study devoted to the road safety [12]. The findings of the data review of the National Automotive Sampling System show that completely deaf and some levels of hearing loss drivers are nine times greater than average person probable to be severely wounded or get killed in an accident involving motor vehicles. The statistic of motor vehicle incidents shows that deaf and hearing impairment drivers are nearly three times more likely as average persons to be involved in a motor vehicle accident.

\section{EXPERIMENT METHODOLOGY}

\section{D Modeling}

3D Modelling was performed using Fusion 360. Fusion 360 enables users to create smooth and precise surfaces with sketch curves, patches, and extrusions. The rendered design of the safety helmet without implementation of the system's components is presented in Figure 1; whereas Figure 2 presents the design of the safety design with the assembly of sound detection mechanism.

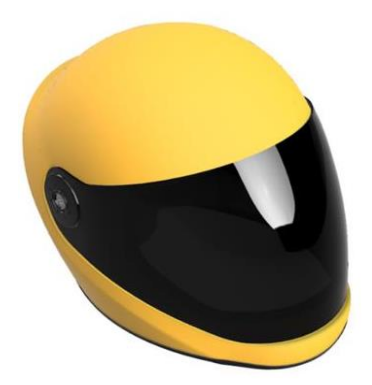

(a)

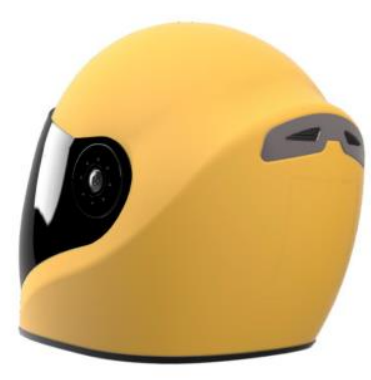

(b)
Figure 1: Rendered design of the safety helmet (a) front view (b) rear view

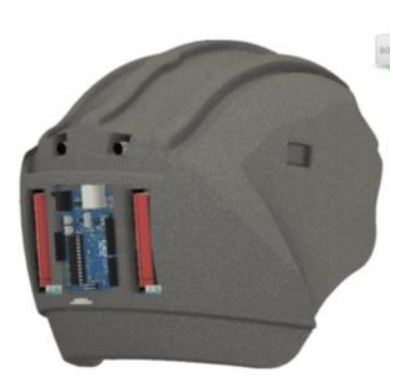

(a)

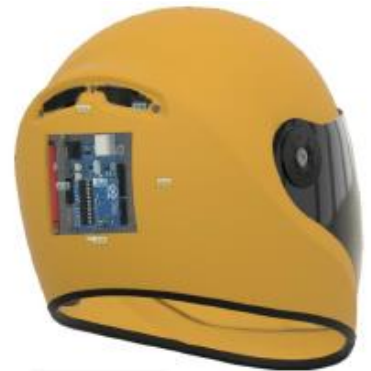

(b)
Figure 2: Rendered design of Safety helmet with sound detection mechanism (a) with shell (b) without shell

\section{Components and System Development}

The designed safety helmet consists of Arduino Uno Board, mic sound sensor module KY-038, potentiometer, light-emitting diode (LED), resistors (330 ohms), and jumper cables. The Arduino Uno Board is used as the controller. The sound sensor detects sound, and the output of sound signals turn the LEDs light on and off depending on the sensitivity set up by using the potentiometer on the sound sensor itself. The LEDs also should light on when sound exceeds the threshold value of $96 \mathrm{~dB}$. This module enables sound detection when the sound has reached the selected set point. The sound is 
detected using the microphone of LM393 amplifier. The sound level can be adjusted by using the built-in potentiometer. As the sound level exceeds the threshold value, the output signal is sent through digital output and illuminates the LED on the system. Figure 3 presents the sketched system diagram.

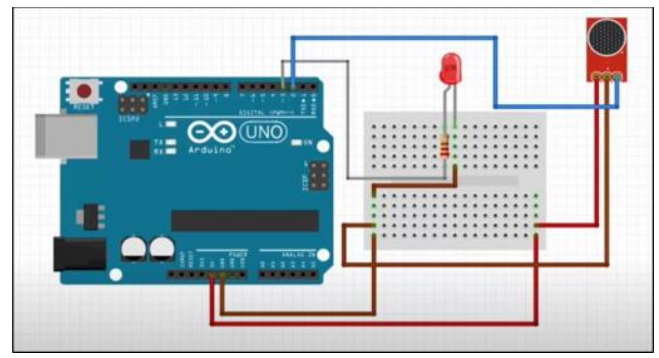

Figure 3: System diagram sketched using Circuit.io

The coding of sound detection mechanism implemented in Arduino IDE is presented in Table 1:

Table 1: Arduino system coding

const int ledpin1=8; const int ledpin2=9; const int
ledpin3=10; const int soundpin=A2; const int
threshold=100; void setup() \{ Serial.begin(9600);
pinMode(ledpin1,OUTPUT);
pinMode(ledpin2,OUTPUT);
pinMode(ledpin3,OUTPUT); pinMode(soundpin,INPUT);
\}
void loop() \{
int soundsens=analogRead(soundpin);
if (soundsens>=threshold) \{ digitalWrite(ledpin1,HIGH);
digitalWrite(ledpin2,HIGH); digitalWrite(ledpin3,HIGH);
\}
else \{
digitalWrite(ledpin1,LOW); digitalWrite(ledpin2,LOW);
digitalWrite(ledpin3,LOW);
\}
\}

An external power supply from 6 to 20 volts is recommended to operate the Arduino board. Power that is less than $5 \mathrm{~V}$ can cause the Arduino board to become unstable. Power that exceeds $12 \mathrm{~V}$ can overheat and harm the board.

\section{Finite Element Analysis (FEA) on Material Selection for Safety Helmet}

The model of the designed safety helmet is simulated and analyzed through finite element analysis (FEA). FEA is performed to reduce the number of the physical prototypes that need to be developed. This allows the designers to optimize components in the design phase, aiming to reduce unnecessary wastage and expenses [13]. In this work, three types of materials were chosen for finite element analysis purpose, namely carbon fiber material, ABS plastic material, and polycarbonate plastic material.

\section{RESULTS AND DISCUSSION}

\section{System Functionality}

Functionally experiment was conducted to detect car horn and motorcycle horn with three distances starting from $4.7 \mathrm{~m}$, which represents the length of a SUV car; $9.4 \mathrm{~m}$, which represents twice of the original distance of the SUV car, and $14.10 \mathrm{~m}$, which represents three times of the than original distance that is proposed in the functionality experiment. Typical car horns are approximately $107-109 \mathrm{~dB}$; meanwhile motorcycle horn is rated about $96-105 \mathrm{~dB}$ [14]. Table 2 presents the results of functionality experiment.

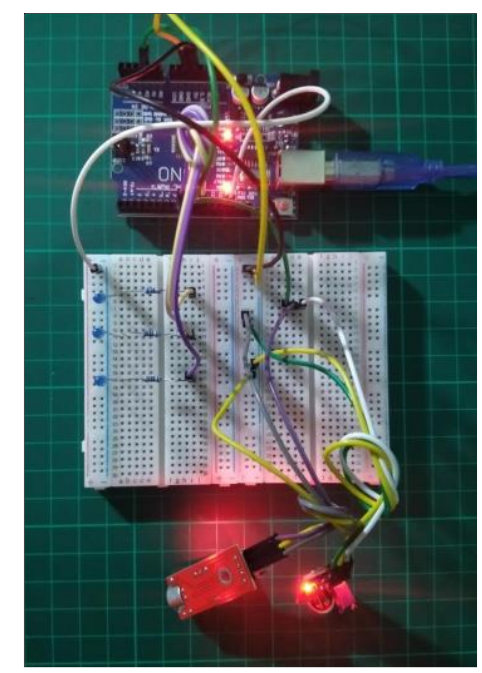

Figure 4: Sound detection mechanism

Table 2: Functionally testing on the sound (horn) detection system

\begin{tabular}{|c|c|c|c|}
\hline \multicolumn{2}{|c|}{ Distance of the vehicle from the device $(\mathrm{m})$} & \multicolumn{2}{|c|}{$\begin{array}{c}\text { LEDs } \\
\text { light up }\end{array}$} \\
\hline Car $(107-109 \mathrm{~dB})$ & Motorcycle $(96-105 \mathrm{~dB})$ & Yes & No \\
\hline 4.70 & 4.70 & $/$ & \\
\hline 9.40 & 9.40 & $/$ & \\
\hline 14.10 & 14.10 & $/$ & \\
\hline
\end{tabular}

\section{Finite Element Analysis for Safety Helmet Modeling}

The Finite element analysis on the design of the safety helmet by using three different materials, was conducted in Fusion 360, as shown in Figure 5 (a), 5(b) and 5(c), respectively. 


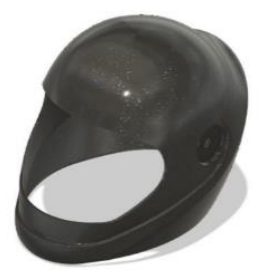

(a) carbon fiber material

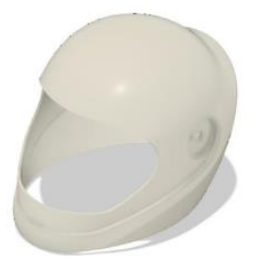

(b) ABS plastic material

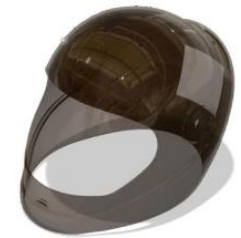

(c) polycarbonate plastic material

Figure 5: Helmet modeling in Fusion 360 simulation platform

The model of the designed safety helmet with respective materials was simulated and tested with $3432 \mathrm{~N}$ load [15]. Three parameters, namely total displacement, stress (Von Mises), and strain (equivalent) were evaluated. Stress and strain are structural assessments that are related to the deformation of solid bodies [16]. The finite element analysis shows that the conventional carbon fiber material has the least deformation (6.174 $\mathrm{mm}$ ) when the force is applied to it vertically with stress of $1014 \mathrm{MPa}$, resulting in the lowest strain of 0.01181 compared to ABS and polycarbonate plastics. Table 3 Figure 6 present the results of the FEA analysis. The results show that carbon fiber is preferably used as the material for the safety helmet.

Table 3: Finite Element Analysis Simulation Results

\begin{tabular}{|l|c|c|c|}
\hline \multirow{2}{*}{$\begin{array}{l}\text { Simulation } \\
\text { Parameters }\end{array}$} & \multicolumn{3}{|c|}{ Type of Materials } \\
\cline { 2 - 4 } & $\begin{array}{c}\text { Carbon } \\
\text { Fibre }\end{array}$ & $\begin{array}{c}\text { Abs } \\
\text { plastic }\end{array}$ & $\begin{array}{c}\text { polycarbonate } \\
\text { plastic }\end{array}$ \\
\hline $\begin{array}{l}\text { Stress-Von } \\
\text { Mises (MPa) }\end{array}$ & 1014 & 1021 & 1021 \\
\hline $\begin{array}{l}\text { Displacement } \\
(\mathrm{mm})\end{array}$ & 6.174 & 366.4 & 360.7 \\
\hline Strain & 0.01181 & 0.696 & 0.6853 \\
\hline
\end{tabular}
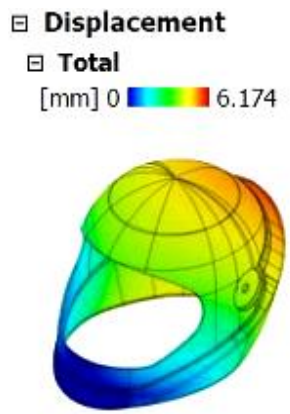

(a) carbon fiber material

$$
\begin{aligned}
& \boxminus \text { Displacement } \\
& \boxminus \text { Total } \\
& {[\mathrm{mm}] \text { o }} \\
&
\end{aligned}
$$

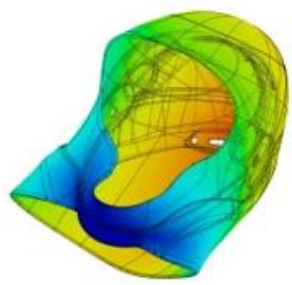

(b) ABS plastic material

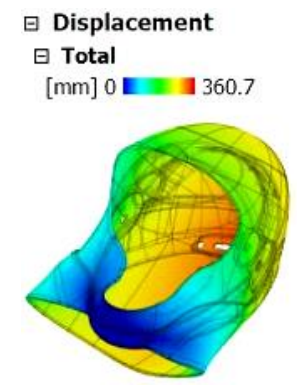

(c) polycarbonate plastic material

Figure 6: Finite element analysis of the designed safety helmet with respective to the materials when $3432 \mathrm{~N}$ load was applied

\section{CONCLUSION}

It is crucial to increase the awareness on the response of hearing impairment and deaf riders to the surrounding sounds, especially horn and emergency siren produced by the vehicles on the road. In this work, the designed safety helmet serves as an alternative alerting system which implement visual approach to aid the hearing impairment and deaf riders.

\section{ACKNOWLEDGMENTS}

The authors acknowledge Universiti Sultan Zainal Abidin for equipment's support.

\section{REFERENCES}

[1] Horvat, M., et al. (2019). Deafness and hearing loss. Dev. Adapt. Phys. Educ., no. June: 217-233, DOI: $10.4324 / 9780203704035-15$.

[2] Goss, B. (2003). Hearing from the Deaf Culture. Intercult. Commun. Stud., vol. XII, no. 2: 9- 24.

[3] Brian, C.J.M. (2016). A review of the perceptual effects of hearing loss for frequencies above $3 \mathrm{kHz}$. International Journal of Audiology, 55(12): 707714 ,

DOI: https://doi.org/10.1080/14992027.2016.1204565

[4] Conto, J. D., Gerges, S., and Goncalves, C. G. D. O. (2018). Hearing risk in motorcycle taxi drivers of a Southern Brazilian City. Speech, Language, Hearing Sciences and Education Journal (Rev. CEFAC), 20(1): 29-36.

[5] Vivoda J. M., Molnar, L. J., Eby, D. W., Bogard, S., Zakrajsek, J. S., Kostyniuk, L. P., St Louis, R. M,. Zanier, N., LeBlanc, D., Smith, J., Yung, R., Nyquist, L., DiGuiseppi, C., Li, G., Strogatz, D. (2021).The Influence of Hearing Impairment on Driving Avoidance Among a Large Cohort of Older Drivers. J Appl Gerontol. Mar 
12:733464821999223.

doi: $10.1177 / 0733464821999223$.

[6] Harvey, E.R. (2008). Deafness: A Disability or a Difference.Health Law \& Policy 2, 1(2008): 4257.

[7] Thomas C.M., Maribeth T. D., Derek J. R. (2019). Hearing Loss in Adults: Differential Diagnosis and Treatment. Am Fam Physician, 100(2): 98-108.

[8] Kuwahara, N., Morimoto, K., Kozuki, K., Kawamura, T. (2008). Emergency Vehicle Alarm System and Vibration Devices for Deaf Drivers by Using LEDS. Journal of Light \& Visual Environment, 32(2):226-229.

[9] Bullough, J., Skinner, N., and Rea, M. (2019). Impacts of Flashing Emergency Lights and Vehicle-Mounted Illumination on Driver Visibility and Glare. SAE Technical Paper 2019-01-0847: 15, https://doi.org/10.4271/2019-01-0847.

[10] Michael, J. F., Daniel, F. B., Joel, M. D. (2008). Effects of Warning Lamp Color and Intensity on Driver Vision. Report of work on Non-Blinding Emergency Vehicle Lighting (NBEVL).

[11] Thorslund, B. (2015). Effect of hearing loss on traffic safety and mobility. Thesis.

[12] Ho, I. C., Chenoweth, L., \& Williams, A. (2021). Older People's Experiences of Living with, Responding to and Managing Sensory Loss. Healthcare (Basel, Switzerland), 9(3), 329. https://doi.org/10.3390/healthcare9030329.

[13] Gordon, M. E., \& Pearson, J. J. (2016). Preliminary Analysis of Roadway Accident Rates for Deaf and Hard-of-Hearing Drivers - Forensic Engineering Application. Journal of the National Academy of Forensic Engineers, 33(1). https://doi.org/10.51501/jotnafe.v33i1.27

[14] Vinod, B., and Saraswathi, K. (2020). Finite Element Analysis and Its Applications in Dentistry IntechOpen, DOI: 10.5772/intechopen.94064.

[15] Department of Environment Malaysia (2019). Guidelines for Environmental Noise Limits and Control (Third Edition).

[16] Bosch Van Den, H. L. A. (2006). Crash helmet testing and design specifications. Technische Universiteit Eindhoven. https://doi.org/10.6100/IR613094.

[17] Pulkit, K., Moumita, M. and Amares, C. (2018). An Overview of Stress-Strain Analysis for Elasticity Equations, IntechOpen-Elasticity of Materials - Basic Principles and Design of Structures, $1-20, \quad$ DOI: 10.5772/intechopen.82066. 